\title{
O STATUS QUO DO LIVRO DIGITAL E O LEITOR POR ELE CONSTITUÍDO
}

\author{
The digital book status quo and its reader
}

El status quo del libro digital y su lector

Carina Luisa Ochi Flexor

Docente/Faculdade de Comunicação

Universidade de Brasília (UNB)

carina.flexor@unb.br

\section{Resumo}

Considerando a natureza da mídia livro digital, o presente artigo objetivou, a partir do status quo do livro-aplicativo e seus respectivos graus de abertura à participação, apontar para os leitores-modelos previstos em suas conformações, antes, demarcadas através dos protocolos de leitura. A partir de Chartier (2011), Manovich (2002), Plaza (2000) e Eco (1988, 1991) e, ainda, partindo de uma perspectiva qualitativa-exploratória, o texto foi tecido aproximando as abordagens teóricas dos objetos empíricos analisados. Enquanto resultado, além de constatar que os estágios de desenvolvimento livresco e seus relativos graus de abertura apontam para a conformação de leitores-modelos distintos, indica, ainda, o fato de que o livro em ambiência digital antes de fixar padrões normativos e organizacionais, amplia suas modalidades de conformação e, consequentemente, os leitores-modelos por estes constituídos.

Palavras-chave: Livro-aplicativo. Protocolos de leitura. Leitor-modelo.

\begin{abstract}
Considering the nature of the digital book, this article aimed, based on the status quo of the application book and its respective degrees of openness to participation, to point to the readers model foreseen in its conformations, previously, demarcated from the reading protocols . From Chartier (2011), Manovich (2002), Plaza (2000) and Eco (1988, 1991) and also, starting from a qualitative-exploratory perspective, the text was woven bringing the discussed theoretical approaches to the observed empirical objects. As a result, in addition to noting that the stages of book development and their respective degrees of openness point to the formation of different model readers, it also indicates the fact that the myriad books in a digital environment before setting normative and organizational standards, expands its conformation modalities and, consequently, the model readers constituted by them.
\end{abstract}

Key words: Appbook. Reading protocols. Reader model.

\section{Resumen}

Teniendo en cuenta la ontología del libro digital, este artículo tuvo como objetivo, basándose en el status quo del libro de aplicación y sus respectivos grados de apertura a la participación, señalar los lectores modelo previstos en sus conformaciones, previamente, delimitados de los protocolos de lectura. Desde Chartier (2011), Manovich (2002), Plaza (2000) y Eco (1988, 
1991) y partiendo de una perspectiva cualitativa-exploratoria, el texto se entrelazó acercando los enfoques teóricos discutidos a los objetos empíricos observados. Como resultado, además de señalar que las etapas de desarrollo del libro y sus respectivos grados de apertura apuntan a la formación de diferentes lectores modelo, también indica el hecho de que la miríada de libros en un entorno digital antes de establecer estándares normativos y organizacionales, expande su modalidades de conformación y, en consecuencia, los lectores modelo constituidos por ellos.

Palabras clave: Appbook. Protocolos de lectura. Lector modelo.

\section{INTRODUÇÃO}

Fortalecendo, ao longo do tempo, os lastros culturais que o elevaram à condição de referência, o livro impresso fez internalizar protocolos de leitura (CHARTIER, 2011) e práticas consonantes com suas bases materiais, históricas e culturais. Uma materialidade que deliberou vestígios condutores da leitura demarcados por autores e editores e que fez determinar não só a relação livro-legente, como colaborou para a consolidação de um leitor por este objeto constituído. Um leitor que fora tecido e reafirmado ao longo de uma longa história e que, ademais as particularidades dos objetos e dos leitores constituídos por/em cada obra, fez gestar, no seio da cultura, um leitor-modelo (ECO, 1988) próprio do livro impresso que, disposto a se entregar a uma experiência antes solitária e silenciosa, acostumou-se a deslizar os olhos sobre a linearidade do verbo - e do próprio objeto -, implicando-se em uma atividade concentrada, do espaço privado e da participação, preponderantemente, dirigida às lacunas interpretativas dadas através dos protocolos de autoria.

O cenário atual para além da ruptura da materialidade tradicional do livro, somada à quebra do polo de emissão, enseja novos protocolos de leitura ${ }^{1}$ e, consequentemente, acaba por tecer um leitor-modelo que, aos poucos, vai se distanciando daquele anteriormente associado ao livro impresso.

Se o livro impresso fez reconhecer que o leitor-ideal/leitor-modelo (CHARTIER, 2011, ECO, 1988) previsto por uma obra é antes tecido em sua concepção através dos protocolos do autor e do editor, a presente pesquisa, ao atualizar - a partir do reconhecimento da natureza da mídia livro digital ${ }^{2}-$, os protocolos de leitura do livro-aplicativo ${ }^{3}$, faz ver que

\footnotetext{
${ }^{1}$ Flexor (2018), considerando a natureza material da mídia livro e os protocolos de leitura de Chartier (2011), aponta para a ampliação dos agentes produtivos que, participando da tessitura do objeto, imprimem vestígios que impactam sobre a leitura, reconhecendo, dessa forma, para além dos protocolos do autor e editor, também os protocolos do sistema e os protocolos na leitura/no espaço.

${ }^{2}$ Refere-se à mudança da materialidade livresca, fazendo ver as lógicas da new media (MANOVICH, 2002), sua conformação dada através dos algoritmos e estruturas de dados.

${ }^{3}$ Refere-se à modalidade dos livros digitais denominados de livros-aplicativos (appbooks) que, diferentemente dos livros-arquivos, se enquadram no universo dos softwares.
} 
este objeto passa a inscrever procedimentos em sua base computacional que, por sua vez, passam a reivindicar, potencialmente, a colaboração do leitor na sua contextura, ampliando a ideia de lacunas que, somadas às interpretativas, abrem-se progressivamente à possibilidade de aportes de conteúdo multimodal e dados, sinalizando para a gradativa abertura do objeto livresco à participação efetiva do leitor e não apenas na produção de sentido.

Tomando como base os graus de abertura da obra de arte propostas por Plaza $(2000)^{4}$, o presente trabalho reconhece também que, à luz do status quo do livro digital, é plausível reconhecer distintos graus de abertura da obra livresca que, à medida que amplia as possiblidades participativas do leitor, faz viabilizar a incidência de vestígios - protocolos na leitura/no espaço - que se endereçam à experiência leitora.

Diante do exposto, o presente trabalho parte da observação da abertura da obra livresca a partir das fases de desenvolvimento do livro em ambiência digital - e seus respectivos lastros estabelecidos pela visualidade -, reconhecendo o estágio de transposição e suas relações de iconicidade, a transfiguração e suas relações de indexicalidade e a transdução e suas relações de arbitrariedade para com a ideia de livro consolidado historicamente.

A abertura de primeiro grau remeteria à polissemia, à pluralidade de leituras e riqueza de sentido, reconhecidas nos livros em transposição - estágio em que se observa fortes relações de iconicidade para com o livro impresso - que se abrem para uma participação, predominantemente, no âmbito interpretativo. A abertura de segundo grau indicaria alterações estruturais e informacionais que vinculam o leitor à obra e que passam a ser reconhecidas em livros em transfiguração, estágio em que se faz notar relações indexicais e que se abrem a uma participação, majoritariamente, aqui denominada de interativa ${ }^{5}$. A abertura de terceiro grau, por sua vez, associada ao estágio da transdução - estágio em que as relações para com o livro impresso se efetivam por lastros assentados na arbitrariedade simbólica -, caracteriza-se por uma participação que é afetada pela coparticipação e intervenção maquínica, como agente

\footnotetext{
${ }^{4} \mathrm{O}$ autor discute a abertura das obras de arte à recepção, identificando três fases produtivas da arte, sendo que a abertura de primeiro grau remete à pluralidade de leituras e à riqueza de sentido; a de segundo grau se relaciona com as alterações estruturais e temáticas que incorporam o espectador de forma mais ou menos radical; e a de terceiro grau, mediada por interfaces técnicas, estaria a colocar a intervenção da máquina como decisivo agente de instauração estética, próprio das imagens de terceira geração.

${ }_{5}^{5}$ Embora todo e qualquer sistema computacional, por si, seja interativo - pois pressupõe que toda ação do usuário implica em outra ação do sistema, resultando em alteração da base informacional, o termo interativo é aplicado para denotar que a ação do usuário aponta, dada a abertura de 2o. grau, para mudanças na estrutura livresca, transformando a informação/modos de apresentação.
} 
decisivo para a agência e presença de protocolos que são demarcados antes na experiência mesma da leitura.

Destaca-se, ademais, as relações de incorporação, quando faz notar que o terceiro grau pressupõe os anteriores, bem como o segundo pressupõe o de primeiro grau, fazendo perceber que tais classificações não são absolutas, do contrário, vislumbra-se apenas reconhecer indicadores de predominância quando, por exemplo, faz ver que quando o livro resguarda em si características qualitativas próximas do seu análogo impresso, observa-se uma participação, predominantemente, dada pelas lacunas interpretativas, embora já se reconheça a presença de simples recursos interativos nos mesmos.

Notadamente, o livro impresso gestou a ideia de um objeto único/totalitário que obedeceu a um encadeamento marcado pela linearidade do verbo, apoiado em estratégias compositivas e estruturais próprias de sua concepção que, por sua vez, colaborou com a constituição de um leitor-modelo particular. Por outro lado, o livro digital - enquanto novidade que se entrega a experimentações e, ainda, frente a natureza material que viabiliza múltiplas espécies de mídia (MANOVICH, 2002) e modos diversos de apresentação -, faz ver uma miríade de leitores-modelos previstos por tais variações.

Nesse sentido, evidencia-se que os estágios livrescos aqui apresentados pretendem servir de clareamento no sentido de se observar quais leitores-modelos estão sendo, deliberadamente, constituídos por esses objetos frente as suas especificidades. Reconhecidos os estágios livrescos, cujos vínculos com seu antecessor histórico, vão variando gradativamente e, ainda, identificando que estes resguardam em si graus de abertura que indicam participações dos seus leitores de distintos graus, é legítimo, então, afirmar que cada estágio livresco acaba por prever ou ajuda a constituir leitores-modelos que lhe são particulares.

Diante desse contexto, a partir de Chartier (2011), Manovich (2002), Plaza (2000) e Eco $(1988,1991)$ e partindo de uma perspectiva qualitativa-exploratória, o texto foi tecido aproximando as abordagens teóricas discutidas dos objetos empíricos analisados, tendo como objetivo identificar os leitores-modelos previstos pelos livros-aplicativos nos citados estágios/aberturas. Destaca-se, entretanto, que assim como os livros podem apresentar maior tendência a um estágio ou a outro, os leitores-modelos aqui delineados basculam de mesmo modo. Registra-se, ainda, que a pesquisa não intuita criar termos arbitrários e/ou novos nomes para velhas discussões, pretende apenas nominar o leitor-modelo a partir daquilo que desponta 
como sobressalente na sua relação com o objeto, referenciando a abertura/participação dos mesmos.

\section{ESTÁGIOS DE DESENVOLVIMENTO DO LIVRO-APLICATIVO E SEUS LEITORES-MODELOS}

\subsection{Semelhança imagética e o leitor participativo-interpretativo}

É legítimo registrar que, embora sejam variadas as possibilidades advindas da interação orientada entre hardware e software, as propostas editoriais que elegem a modalidade livro-aplicativo nem sempre fazem uso dos recursos disponíveis, assim como nem sempre se apresentam consonantes com as demandas e expectativas dos sujeitos imersos na cultura contemporânea.

Tal questão faz notar que muitos appbooks mantêm vínculos majoritariamente icônicos com as versões impressas, o que faz perceber que as representações digitais, respaldadas na semelhança qualitativa sustentam a manutenção de layouts de capa e materiais similares ao impresso, inclusive apresentando simulação de textura de papel, recursos gráficos e acabamento, mantendo, por exemplo, estruturas como marcadores de página, que, a priori, perdem a sua função original quando da passagem para o meio digital.

Se através da camada cultural das interfaces gráficas, a partir dos protocolos de edição, observam-se obras que antes se ancoram na mimese, no âmbito da camada computacional, em especial no que se refere aos protocolos do sistema, observa-se que as instruções inscritas reverberam em procedimentos que igualmente emulam o impresso, autorizando o leitor a interagir com estes de uma maneira muito próxima ao impresso e, nesse sentido, o leitor é convocado a repetir o movimento de passar de páginas, de acompanhar marcações que reforçam a cadência da leitura etc. Figuram enquanto estratégias de mimese, também, recursos como pop-ups e harlequinades que - embora estejam aquém das possibilidades de simulação disponíveis no meio digital -, outrora se apresentavam enquanto técnicas recorrentes no meio editorial para incorporar efeitos de movimento e tridimensionalidade e que já, à época, sinalizavam para uma participação que extrapolava, em alguma medida, a interpretativa.

Diante desse primeiro estágio, os modos de apresentação do livro podem ser tidos enquanto incipientes, visto seu forte vínculo para com as referências anteriores, caracterizando, desse modo, enquanto primeira fase de conversão livresca digital a 
transposição que, como diz o termo empregado, transpõe as lógicas estruturais e organizacionais do impresso para a base digital, salvaguardando aspectos do objeto histórico tanto na camada cultural, via semelhança imagética, quanto na camada computacional, gestando práticas que resguardam certa simulitude. O livro transposto estabelece um vínculo sustentado pela semelhança no campo da visualidade, fazendo manter certos elementos que, mesmo ocasionalmente abstidos de sua função original própria do impresso, se estabelecem enquanto via de acesso ao referente.

Essas questões podem ser observadas em The Tale of Peter Rabbit (Figura 1) que, em sua versão digital, mesmo com a incorporação de funções inexistentes no impresso - como a narração e animações sensíveis ao toque -, evidencia uma pronunciada ancoragem nos modos de apresentação da matéria das primeiras versões impressas. Os vínculos vão desde a manutenção do layout de capa, folha de rosto, páginas espelhadas, estilo das ilustrações e mesmo a simulação dos harlequinades em detrimento dos recursos de interação próprios dos recursos digitais, assim como o reforço da linearidade que é conferido por marcadores que vão destacando as palavras sincronicamente à sequência da leitura.
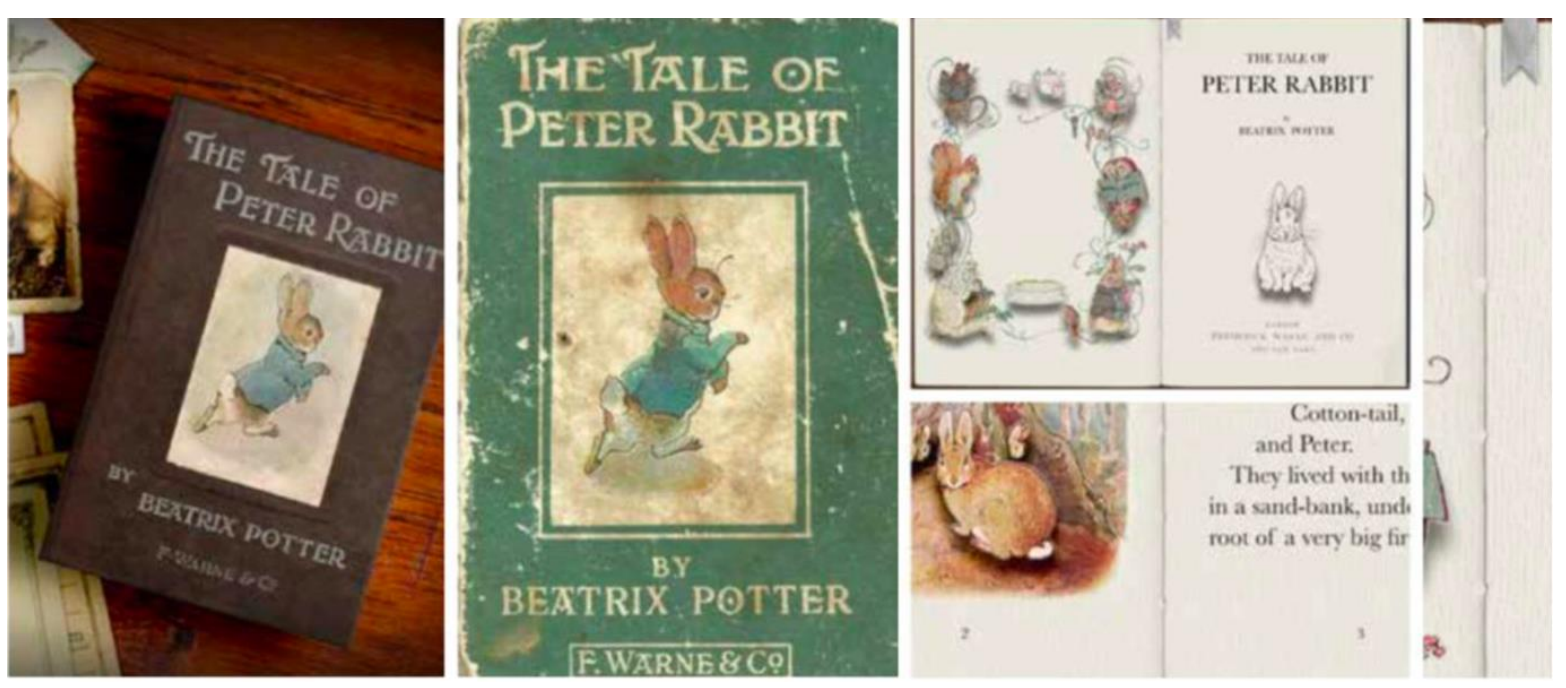

Figura 1 - Tela de abertura do appbook, capa da primeira edição de 1901 e telas do livro-aplicativo com página dupla, folha de rosto, fólios, simulações visuais de costura e acabamento.

Fonte: acervo pessoal.

Os appbooks The Tale of Tom Kitten e The Tale of Jemima Puddle-Duck, de mesma autoria, de modo similar, mantem vínculos com o objeto histórico, seja no reforço dado pelas marcações de palavras sincronicamente à narração, seja no passar de páginas e mesmo quando o marcador do livro se presta ao resgate do sumário que é dado a partir da visualização de todas as folhas espelhadas do livro. Destaca-se que as interações, acompanhadas da matriz 
sonora, quando não simulam movimentos já alcançados pelo livro impresso, fazem mover objetos e personagens sem, contudo, alterar a estrutura do objeto em si. A abertura para o aporte informacional por parte do leitor é também restrita às possibilidades advindas do impresso, como ao permitir que o leitor insira seu nome em "This Book Belongs to" (Figura 2).
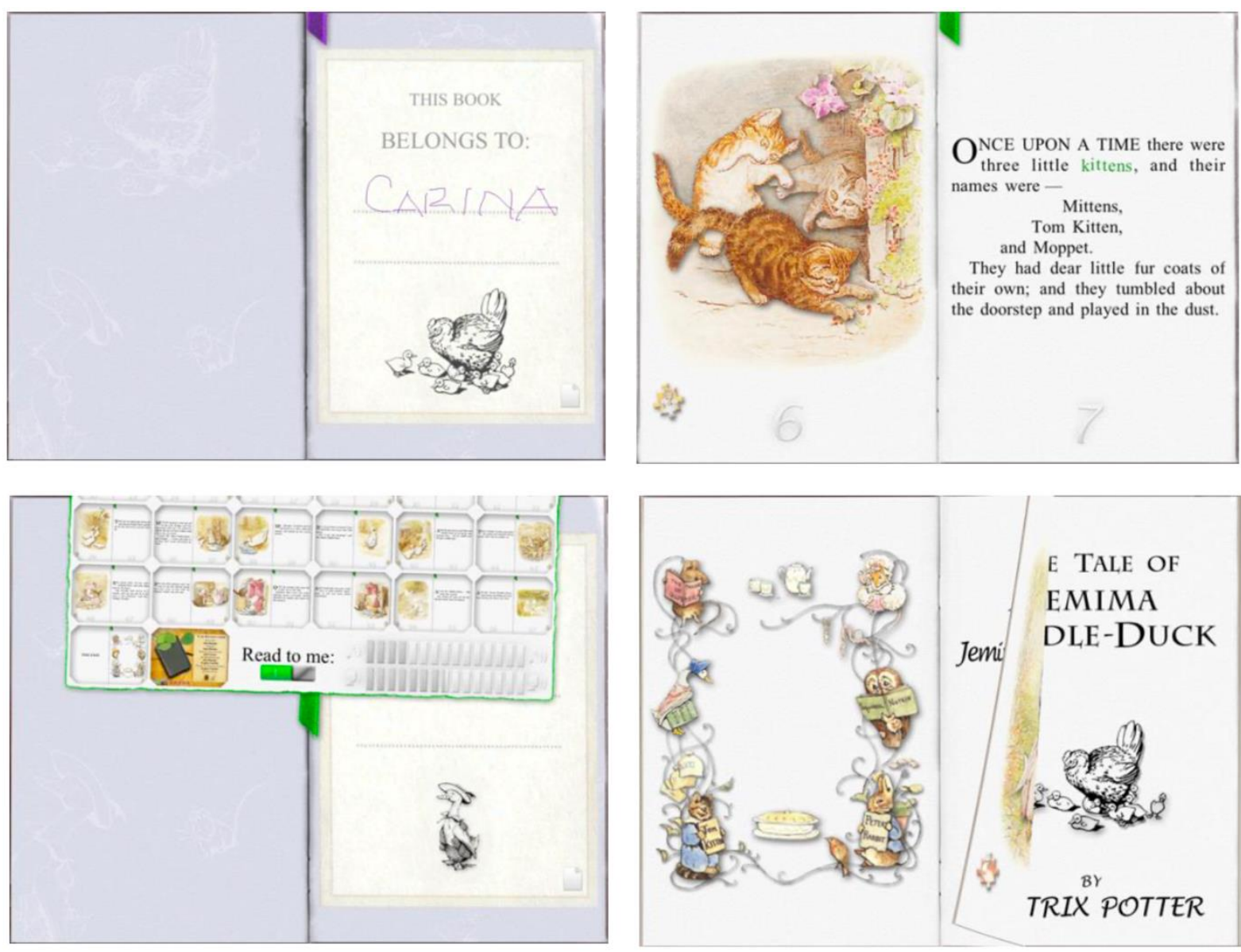

Figura 2 - Possibilidade de aporte informacional, a palavra em destaque indica a narração, marcador de página que serve de resgate ao sumário em páginas espelhadas e simulação do passar de páginas.

Fonte: acervo pessoal.

Ademais simule visualmente a textura do papel, tais livros mantem ainda vínculos próximos do impresso no que diz respeito aos modos de acesso e uso, mantendo, a partir do dicionário de gestos, a noção de passar de páginas. Essas questões são reforçadas pela predeterminação dos modos de visualização de tela - horizontal apenas -, nos quais se mantêm as proporções e disposições espaciais dos elementos verbovisuais de forma similar ao formato aberto do impresso, conservando os aspectos estruturais, a organização do conteúdo textual em blocos emoldurados pelas margens e a presença do fólio. 
Observa-se que os livros em estágio de transposição, ao ser tecido através de protocolos de leitura - do autor, do editor e do sistema - que sustentam a referida mimese, acabam por tecer, em suas engenharias, um leitor-modelo que aceitaria um pacto de leitura $(\mathrm{ECO}, 1988)$ que estaria vinculado a lógicas próximas do impresso e, portanto, aquém dos recursos que o meio propicia.

Duplamentente ancorado na transcrição do livro impresso - através dos vestígios demarcados na camada cultural e também computacional -, o estágio da transposição prevê, a partir da abertura de primeiro grau da obra, um leitor-modelo que é nele e por ele constituído que, a priori, estaria disposto a ter sua participação mediada, prioritariamente, pelas lacunas interpretativas dadas pelos protocolos de autoria e brechas interativas dadas pelos protocolos de edição e do sistema.

Um leitor-modelo participativo-interpretativo ${ }^{6}$ que aponta para um nível de atuação que, respaldada pelos procedimentos inscritos no sistema, estaria a cooperar interpretativamente a partir das brechas dadas pelos protocolos de leitura e que estaria inclinado a implicar o corpo no passar de páginas e no percorrer das linhas com os olhos e, ainda, propenso a interagir com um sistema em que suas ações não implicam em mudanças da/na estrutura do objeto. Um leitor gestado por um objeto que mantem signos duráveis (SANTAELLA, 2013) e que não se alteram apesar da interatividade própria do meio, permitindo, apesar da passagem para o meio digital, que o mesmo possa ser lido contínua e repetidamente, assim como sua versão análoga. Um leitor previsto pela tessitura do objeto que, além de observar a cadência das palavras, própria da leitura linear do impresso, ainda dialoga com imagens que, de mesmo modo, apesar de já se prestarem como ponto de acesso às tímidas interações, resguardam modos de apresentação - estilística e de articulação com o verbo - bem próximas dos objetos predecessores.

À luz da experiência da leitura, se, por um lado a adoção do termo livro, pela via da arbitrariedade simbólica se dá pela dimensão qualitativa-icônica na tentativa de capturar a atenção dos leitores iniciantes para o novo meio, por outro, aponta para dissonâncias para com as expectativas dos leitores já em estágio de letramento digital mais avançado. Se por um lado esse contexto aponta para simulacros livrescos, réplicas incoerentes à lógica do meio digital, de outro, criam uma zona de conforto inicial para aqueles sujeitos recém-chegados à

\footnotetext{
6 Nomenclatura adotada em razão de um posicionamento contrário à ideia implícita nas palavras "contemplativo" e "passivo" utilizadas por alguns autores, uma vez que, conforme pontua Eco (1991), a participação do leitor junto à obra está distante de ser passiva, uma vez que esta é constituída na própria leitura.
} 
ambiência digital, permitindo que o know-how adquirido com a experiência da leitura do impresso sirva de ponte para o desbravar de novas experiências.

\subsection{Multirreferencialidade e o leitor participativo-interativo}

Assentadas as primeiras manifestações livrescas em contexto digital com os referidos livros transpostos, em processo constante de mutação em direção à incorporação dos pressupostos da cultura digital, os appbooks vieram assumindo distintas facetas, ilustrando, sobretudo, o estágio experimental e exploratório dos modos de produção e acesso a esse objeto. Se em um primeiro momento, a similitude se mostrou base, em um segundo estágio, observa-se uma dada tendência à desconfiguração das estruturas tradicionais de outrora e um deslocamento da referencialidade imagética para outros objetos não livrescos. Caracterizando o estágio de transfiguração do objeto livresco diante dos dispositivos de leitura e da cultura que o circunda, sobre a camada cultural das interfaces gráficas, passou-se a notar não só uma organização sintática respaldada pela analogia qualitativa a sites de internet, menus de DVD e jogos, por exemplo, como, sobretudo, lógicas de acessos particulares ao hipertexto.

Ao abdicar do lastro icônico para com o impresso, os livros digitais parecem começar a fazer jus a sua transmutação material e passam a experimentar outras modalidades de acomodação do conteúdo e a propiciar outras formas de experienciar o objeto. Para além da camada cultural e dos modos de apresentação nas interfaces gráficas multicontaminadas por distintos produtos e linguagens, o livro em estágio de transfiguração inscreve em sua camada computacional, a partir dos protocolos do sistema, uma multiplicidade de instruções que orientam procedimentos que observam o hibridismo próprio da rede.

Se, por um lado, a camada cultural fez mesclar sintaxes e gramáticas de múltiplos produtos da cultura, inclusive, do objeto livresco, por outro, na instância da camada computacional, faz ver procedimentos que ora se aproximam de tarefas antes vinculadas ao impresso, outrora orientados por instruções particulares dos seus distintos referentes. Ao atentar para tal questão, inclusive, observa-se a multiplicidade de atividades que se somam à experiência do ler - como jogar, por exemplo -, bem como a alternância entre os modos de leitura linear e multilinear, assim como a predominância de imagens em movimento, próximas das cinematográficas, ou que se fazem movimentar através do acionamento interativo do sistema. Livros que absorvem referências visuais que incorporam funções e estilos dos produtos para os quais apontam, tornando o terreno livresco complexo, ainda mais por permitir aportes de conteúdo multimodal, como anotações, narrações e inserção de 
imagens por parte do leitor, autorizando que cada legente altere/personalize, pelo menos para si, o conteúdo informacional e seus modos de apresentação.

Tais tentativas, longe de atingir um caráter identitário para o livro digital, mais se aproximam de replicações indiscriminadas de modelos midiáticos diversificados, somadas às bases editoriais que legitimaram o livro histórico, assumindo, assim, estruturas polimorfas, como múltiplas espécies de mídia (MANOVICH, 2002). É legítimo, entretanto, reconhecer que os elos para com o impresso, ainda que pela via da manutenção parcial de um ordenamento do conteúdo ou da replicação de estruturas diagramáticas do impresso, permitem que estes objetos sejam reconhecidos como livros, mesmo quando seus objetos dinâmicos variam em gênero, número e intensidade em relação ao impresso.

Assim, viabilizado pela base comum digital de distintos produtos culturais, os livros transfigurados parecem prescindir da ancoragem quase que exclusiva do qualitativo-icônico com seus análogos impressos, em detrimento de uma vinculação mais diluída para com estes e demais mídias conviventes. Estas relações se mostram estruturadas a partir da manutenção de elementos outrora particulares à cultura livresca e que, embora posteriormente aplicados em objetos midiáticos de outras naturezas, retornam ao livro digital como marcadores diluídos entre o livro e as demais mídias. Tal questão pode, por exemplo, ser observada através da lógica presente no menu de um site, na sequência de cenas de um DVD organizadas em capítulos, no diagrama de cabeçalhos e rodapés de páginas na internet que, mesmo abstida de similaridade formal, alusões singulares e/ou arbitrárias ao livro, se apresentam como elementos por demais recorrentes no estágio de transfiguração livresca.

A exemplo, pode-se citar o appbook The Waste Land do T. S. Eliot (Figura 3) que, diferente da versão impressa original de 1922, possibilita que o usuário possa ter acesso ao mesmo texto de diferentes maneiras, seja através de narrações de artistas reconhecidos, interpretado teatralmente por dramaturgos, comentado por críticos literários ou lido nos próprios manuscritos do autor. Toda informação está conectada de modo que o leitor possa alternar entre as diferentes modalidades de apresentação do conteúdo, ampliando, assim, a experiência da leitura. 


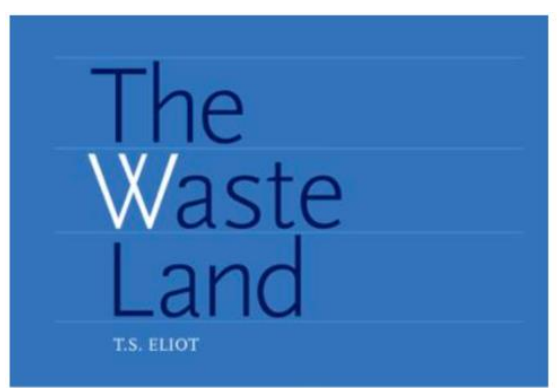

$\Delta=$

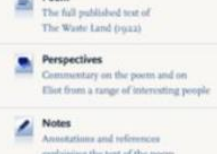

$1=$

2 $\lim _{n \rightarrow \infty}$

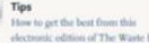

chors sernucs

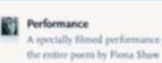

$s=$

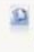

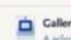

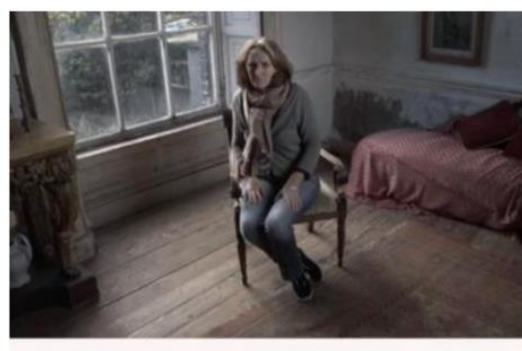

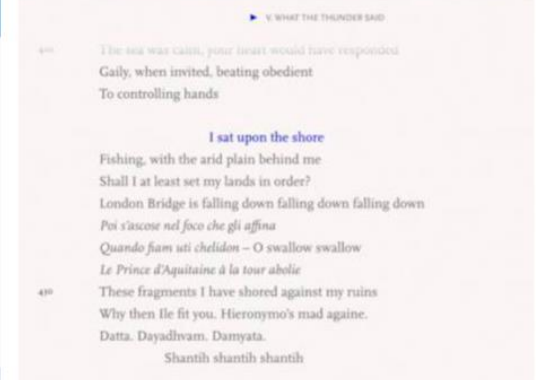

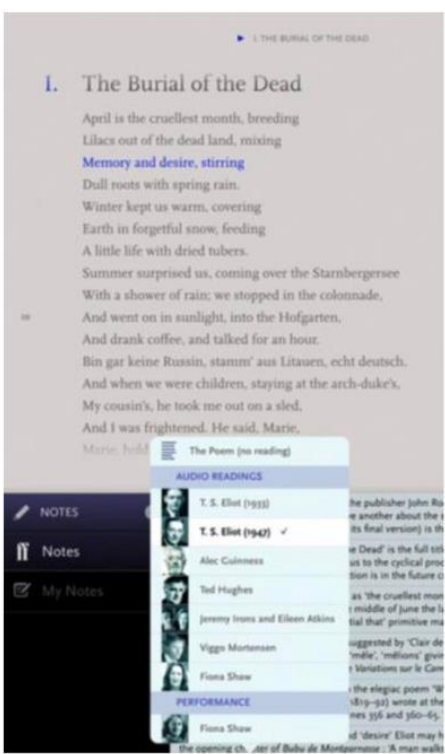

Figura 3 - Na tela de apresentação observam-se distintas maneiras de ler o livro, dentre elas uma performance da atriz britânica Fiona Shaw.

Fonte: acervo pessoal.

Sobressai-se o fato de que, apesar da interface gráfica inicial manter um nível de iconicidade mais próximo a uma homepage e dos modos de acesso remeterem indexicalmente a um CD-ROM, o lastro para com o objeto livro permanece na organização do conteúdo em páginas numeradas, hiperlinks ordenados em notas de rodapé e menu com uma lógica próxima do sumário. Nesse caso, a articulação com o objeto histórico se estabelece de modo mais diluído do que nos livros transpostos e sua estrutura expandida, ao implementar outras lógicas e recursos que permitem a escrita dos legentes - frente a abertura de segundo grau -, passa a possibilitar transformações no próprio objeto, tornando-o um livro devir.

Configurações possíveis de caracterizar o estágio de transfiguração também podem ser observadas no appbook Nautilus ou mesmo o livro-aplicativo Os Dez Amigos, do Ziraldo. Soma-se a essa categoria, ainda, os livros-aplicativos cujo objeto para o qual sinalizam não diz de um livro, mas de um jogo eletrônico para consoles, por exemplo, ou para obras cinematográficas como a premiada animação The Fantastic Flying Books of Mr. Morris Lessmore (Figura 4). Diferente dos appbooks exemplificados até aqui, o livro impresso The Fantastic Flying Books of Mr. Morris Lessmore surgiu apenas após o lançamento da sua versão digital. Apesar da narrativa fílmica estar alicerçada na paixão pelos impressos, o appbook se reporta diretamente ao cinema. O conteúdo textual inserido é uma adaptação da película e as interações procuram estabelecer relações por semelhança e particularidade à experiência vivida no cinema. O leitor é convidado a interagir, seja tocando a trilha em um piano que mostra as notas para que o leitor reproduza, seja "caindo" com o personagem no 
mundo da leitura, a partir dos recursos de giroscópio e acelerômetro do dispositivo de leitura. As relações qualitativas encontradas para com o objeto que representa estão a serviço da ampliação da experiência vivida no cinema, a partir da mídia-livro e são percebidas, sobretudo, pela manutenção da capa, linearidade da narrativa e modos de acesso particular ao livro histórico.
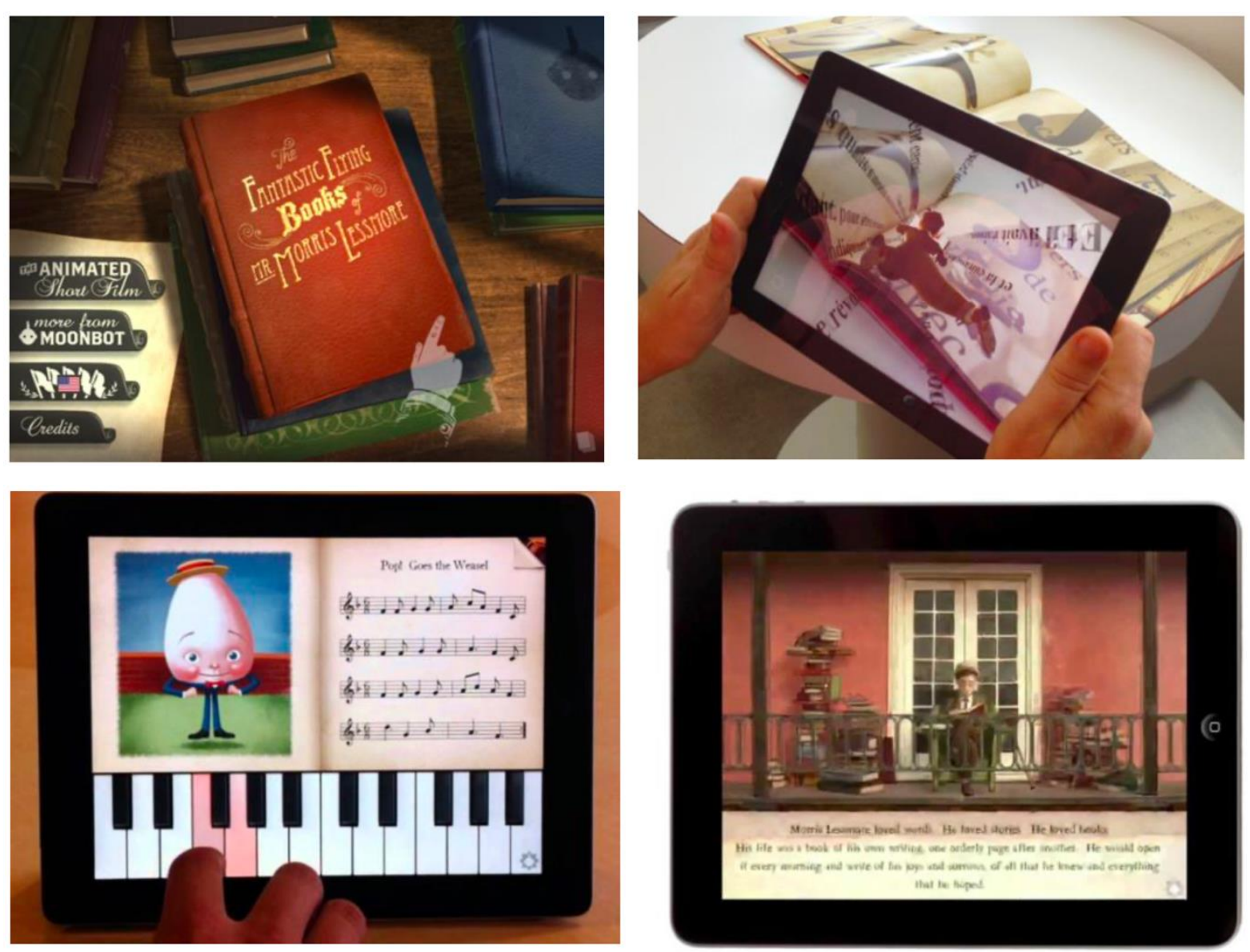

Figura 4 - Appbook The Fantastic Flying Book of Mr. Lessmore e as possibilidades de interação. Fonte: acervo pessoal.

Diante do exposto, o livro-aplicativo em estágio de transfiguração faz notar um leitormodelo tecido pela e na obra que estaria disposto a ter experiências que vão além da zona confortável e assentada pelo livro impresso, um leitor propenso a descobrir intuitivamente os modos de navegação e acionamento do sistema - que são antes contaminados por referências e linguagens advindas dos jogos, web, cinema etc -, e, ainda, inclinado a compactuar com interações que permitem maior participação em termos de aporte de conteúdo, vendo suas ações obterem resposta do sistema, transformando o livro em pequena medida. Esse estágio de conformação livresca estaria a delinear um leitor-modelo aqui denominado de 
participativo-interativo, um leitor do livro em transição e que se permite contaminar por múltiplas linguagens advindas de outros produtos culturais, desvinculando-se, aos poucos, dos lastros seguro das referências qualitativas do impresso. Um leitor que, encontrando obras de segundo grau de abertura, estaria disposto a extrapolar as lacunas interpretativas e interações que emulam o impresso, passando a lidar com a resposta do sistema às interações realizadas, pressupondo a ideia de que as ações do sujeito promovem mudanças na estrutura livresca e, sobretudo, viabilizam distintas formas de navegar pelo conteúdo livresco.

\subsection{Arbitrariedade e o leitor participativo-colaborativo}

Os caminhos de análise até aqui delineados estão longe de serem observados enquanto fenômenos isolados, de forma inversa, verifica-se que o livro digital é, desde sempre, um híbrido que se manifesta a partir de uma miríade. Diferente dos impressos que mantêm uma pronunciada tradição normativa, os appbooks podem se apresentar em diferentes graus de referencialidade ao análogo impresso e mesmo em relação a outros produtos da cultura, incorporando, diversificadamente, estratégias de acesso ao conteúdo que podem se assemelhar a distintos objetos, salvaguardando para com estes e mesmo o livro, um espectro de variações em iconicidade e indexicalidade.

Essa questão sinaliza para o fato de que, embora possa se reconhecer, nos dispositivos de leitura e em suas interfaces gráficas, potências para a conectividade e colaboração, é possível observar que os livros-aplicativos, quando não se mostram réplicas transpostas, apresentam-se referendados qualitativa ou indexicalmente na fisicalidade do livro histórico, caminhos contraditórios à ideia de obra nativa da cultura digital. Acerca dessa questão, conforme registra Lévy (1999, p. 147), a obra interativa demanda o envolvimento daqueles que a experimentam, "o interagente participa da estruturação da mensagem que recebe [...] são obras-fluxo, obras-processo, ou mesmo obras-acontecimento, pouco adequadas [...] à conservação".

Para além dos lastros qualitativos ou indexicais ainda fortemente articulados na concepção da matéria livresca, observa-se, em muitos livros, a manutenção dos modelos massivos de transmissão da informação que mantém, em boa medida, os dois grandes fatores clássicos de totalização das obras que Lévy (1999) registra: a totalização por intenção do autor e a totalização por extensão pela gravação. Os appbooks disponíveis no mercado parecem não participar integralmente dos rizomas próprios do ambiente digital, na medida em que não assumem, muitas vezes, a dinâmica autopoiética dos atuais modelos em rede. 
Reconhecendo, diante do exposto, que o estágio inicial do fenômeno livro-aplicativo é marcado por um espectro variante nos modos como este se reporta aos seus análogos impressos, o lastro desse fenômeno para com a cultura livresca está, em boa medida, assegurado pelo caráter legislativo do símbolo livro. A arbitrariedade do termo em relação ao seu referente, ao ser culturalmente legitimada, viabiliza, por hora, uma dada liberdade de transformação dos objetos dinâmicos do signo livro, permitindo que a miríade de experimentações editoriais no cenário digital se movimente dinâmica e freneticamente em detrimento da manutenção do termo (FLEXOR, 2012).

Assim, o livro digital inaugura uma nova fase da cultura editorial - o estágio de transdução -, que apesar de poucos os experimentos, fazem avançar o cenário livresco. Destaca-se The Pickle Index que, na tentativa de se apresentar aberto à interpenetração de outras obras na rede, bem como para a exploração ativa e colaboração dos sujeitos interatores, prevê protocolos do sistema que permitem a participação colaborativa dos leitores que incidem vestígios sobre a experiência da leitura. Contemplando uma narrativa videográfica, o livro - no que se refere aos protocolos demarcados nas camadas cultural e computacional -, faz ver referências distantes do livro histórico, embora intercale modos de acesso que basculam entre o modo linear e multilinear e manutenha a lógica importada de capítulos e sequencialidade de leitura, por vezes, imposta por recursos visuais. Esses livros permitem-se contaminar por outras referências, quando se observa menus próprios da web que se mesclam com abas de aplicativos, bem como sistemas de avançar e retonar comum a CD-ROMs e sites. Nesses exemplos, observa-se um pronunciado distanciamento das referências visuais do impresso, fazendo plasmar, nas interfaces gráficas, estruturas visuais e organizacionais que desconfiguram a ideia do livro impresso e instauram uma linguagem que, embora contaminado por múltiplos produtos culturais, ao desconstruir em definitivo grande parte da lógica anterior, fazem ver sintaxes mais consonantes com a cultura digital.

Para além das citadas desvinculações instauradas na camada cultural das telas luminescentes, o que separa o estágio de transdução dos demais, sobretudo dos livros transfigurados, é o fato de que a obra - cuja abertura se categoriza como de terceiro grau estaria prevendo procedimentos que apontariam para lógicas participativas que vão além das tradicionais interações ilustradas no estágio anterior, bem como a participação interpretativa prevista pelo primeiro estágio apresentado. Os livros transduzidos seriam aqueles que, previstos por protocolos inscritos na camada computacional, estariam a permitir a incidência de protocolos na leitura e, mais além, protocolos no espaço. 
Diante do exposto, é possível, aferir que os appbooks em estágio de transdução parecem gestar um leitor-modelo participativo-colaborativo que - dada a abertura de terceiro grau - participa a ponto de demandar vestígios endereçados a outros leitores, construindo a partir da tessitura da obra, de certa forma, os seus próprios leitores-modelos. Tal questão se dá pela possibilidade dada pelos protocolos do sistema que inscrevem procedimentos que permitem a colaboração dos leitores que passam a cooperar com aportes de conteúdo multimodal e dados rastreados pelos softwares e hardwares de leitura, configurando o que foi denominado de protocolos na leitura. Estes livros, por vezes, preveem uma abertura que, dada a ubiquidade dos dispositivos de leitura, permitem que incidam sobre a experiência da leitura, índices denominados de protocolos no espaço.

No que se refere ao destacado The Pickle Index (Figura 5), embora cada um - livros impressos e livro-aplicativo - tenha sido projetado para promover uma experiência autônoma, o efeito combinado pode se dar de maneira sinérgica. Os leitores são convidados a relacionar as ilustrações de cada volume que conta, a partir dos pontos de vistas de dois personagens, a mesma situação, retratando os modos de ver particular de cada um sobre o mesmo contexto.
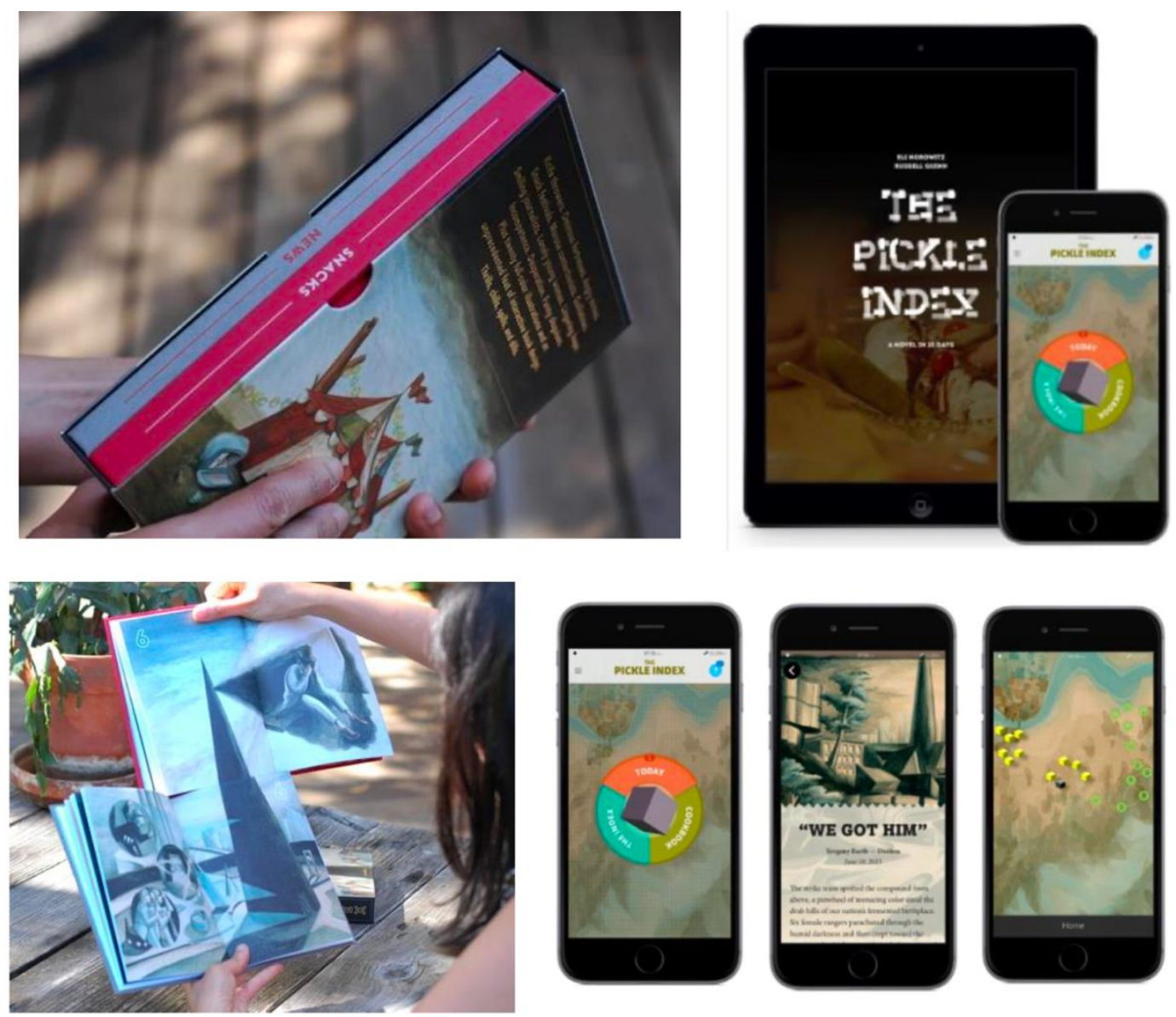

Figura 5 - Relações de complementariedade dada pelas ilustrações que, na narrativa, evidenciam pontos de vista dos distintos personagens. À direita, o livro-aplicativo. Fonte: acervo pessoal. 
O aplicativo permite que o leitor experimente a história de "dentro para fora", assumindo o papel de "cidadão que vivencia a história" à medida que ela se desenrola em tempo real e, por essa razão, suas intervenções direcionam o sentido que a narrativa vai tomando. Os leitores são autorizados a colaborar com a narrativa, em pontos que se mostram georreferenciados e a colaboração dos muitos leitores se mistura aos distintos modos de acessar a narrativa, que se dão através da leitura de perguntas e respostas, alertas de notícias e um sistema de pontos de cidadania que classifica cada leitor, ilustrando seu grau de participação com a narrativa. Resultando em uma experiência exploratória, o aplicativo joga com a serialização, apresenta minijogos, permite a participação do leitor e gera um sistema de upvoting que mede e publica o grau de "cidadania" de cada interator que, desse modo, parece pertencer ao mundo narrativo. Destaca-se que embora seriada e controlada do ponto de vista da liberação de um "capítulo" por dia, o sistema ainda permite que o leitor, a depender da sua atuação na narrativa, possa conquistar um meio de avançar na história mais rapidamente, o que ilustra mais uma forma da narrativa se apresentar de modo particular a cada legente.

The Pickle Index combina storytelling com geocaching, permitindo que partes da história só possam ser acessadas em locais específicos que o leitor é convidado a procurar, como trechos das ficções que são escondidos e que levam o leitor a percorrer espaços do mundo físico, onde habita, para encontrá-los, fazendo com que o espaço que habita passe a existir também no universo ficcional. Se uma narrativa pode se estender para múltiplos espaços, levando o leitor a literalmente viajar com seu livro para encontrar uma história ou trecho ou mesmo acessar uma narrativa ao fazer login no Google Earth, notadamente, as fronteiras da geoficção avançam criando formas que permitem a interação entre os leitores e entre os espaços e a narrativa. Esse aspecto viabiliza a frivolidade dos elementos dinâmicos que são apresentados ao sabor da experiência particular de cada legente, criando uma espécie de dependência de quem está lendo, onde e quando. Esse cenário sinaliza para um livro que permite a incidência de vestígios que são antes demarcados pelas andanças leitoras onde o espaço físico implica em índices que interferem na atividade do ler, através dos protocolos no espaço. Compreendendo que os livros também leem seus leitores - capturando dados durante a experiência do ler -, o exemplo exposto, usando pouco do que potencialmente se tem com os algoritmos atualmente, recolhem informações particulares de cada leitor para direcionar os

\footnotetext{
${ }^{7}$ Refere-se a uma espécie de passatempo ao estilo "caça ao tesouro", configurando-se como uma atividade em que os praticantes tentam encontrar pequenos recipientes, chamados de geocaches, usando receptores GPS e partilhando suas experiências na rede.
} 
caminhos que serão trilhados por cada um desses, bem como para sugestionar outras publicações criadas pelos mesmos idealizadores.

Destaca-se que experimentos, como o ilustrado, sinalizam para os protocolos na leitura e no espaço, prevendo um leitor-modelo disposto não só a promover mudanças significativas e constantes em um objeto que não se totaliza - do contrário, configura-se obra em movimento (Eco, 1991) -, como, sobretudo, propenso a compactuar com aspectos que se dirigem a sua privacidade. Constituído em sua própria tessitura, os livros transduzidos corroboram com a constituição de um leitor-modelo participativo-colaborativo disposto a interpretar, interagir e a colaborar com aportes de conteúdo multimodal e dados, transformando por certo o objeto livresco e as relações ali implicadas. Um leitor tecido pela e na obra e que estaria propenso a ultrapassar as lacunas interpretativas - permanecendo em estado de prontidão cognitiva -, estando inclinado a colaborar com aportes efetivos de conteúdo e dados capturados pelos softwares e hardwares de leitura. Um leitor que se implicaria em ler, escrever e compartilhar suas produções com outros legentes, assim como compactuar com as mudanças sofridas pelo livro diante das intervenções de outros legentes e espaços de leitura, vendo na interação com outros sujeitos - leitores e mesmo autores e editores - um espaço-tempo de convergência de múltiplas experiências além da leitura. Um leitor que mesmo acessando uma estrutura interfacial que muito se descola das referências anteriores, consegue manter o lastro simbólico do livro e, nesse sentido, estaria disposto a usufruir de tarefas que extrapolam a leitura, avançando para uma escrita multimodal, participando de jogos, mídias sociais, dentre outras estratégias incorporadas a esse tipo de livro.

\section{CONSIDERAÇÕES}

À guisa de algumas considerações finais, tendo em vista as reflexões alcançadas com o desenvolvimento dessa investigação, pode-se inferir que a natureza material do livro em contexto digital vem, paulatinamente, reconfigurando, de forma profunda, o objeto em si e as práticas em seu entorno.

Diferentemente do livro impresso que marcou o tecido social com um modelo livresco hegemônico e um leitor-modelo por este constituído, é possível inferir que os distintos estágios de desenvolvimento livresco em ambiência digital e seus respectivos graus de abertura apontam para a conformação de leitores-modelos particulares, indicando, ainda, o 
fato de que o livro-aplicativo antes de fixar padrões normativos e organizacionais próprios do livro digital, amplia suas modalidades de conformação - como espécies de mídia (MANOVICH, 2002) - e, consequentemente, os leitores-modelos por estes constituídos. Esse aspecto, de certo, aponta os distintos atores implicados na tessitura livresca e os distintos protocolos imputados na matéria que estariam, assim, a guiar as condutas leitoras.

Por fim, ressalta-se que as mudanças na estrutura do objeto livro passam a demandar do leitor movimentos de cooperação específicos que, muitas vezes, requer ultrapassar o nível da interpretação, convocando-o a participar da sua feitura, borrando fronteiras entre as instâncias autoral e leitora e transformando a experiência da leitura, outrora interpretativa, em uma experiência ativa de co-criação. O que essas obras exigem, como condição para sua efetivação, é que este leitor, nela e por ela construída, ocupe momentaneamente o lugar do escritor, conformando assim a sua própria experiência de leitura-escrita, bem como fruiçõesproduções vindouras. Ao postulado "o leitor-modelo constitui um conjunto de condições de êxito, textualmente estabelecidas, que devem ser satisfeitas para que um texto seja plenamente atualizado no seu conteúdo potencial” (ECO, 1988, p. 45), seria possível acrescentar que, em se tratando do livro digital em seu estágio de transdução, tais condições de êxito incluem não apenas uma atividade de atualização, mas se configuram como intervenção, como realização, como criação, enfim. Nestes objetos, os "espaços em branco", os "interstícios a serem preenchidos" (ECO, 1991, p.37) que caracterizam qualquer texto abandonam seu sentido metafórico e tornam-se, concretamente, elementos da sua estrutura. Nestas obras, os "indícios de uma intenção" (ECO, 1991, p. 25), os "protocolos do autor" (CHARTIER, 2011) possíveis de serem observados são as lacunas (literais) nas quais os leitores-inscritores devem depositar (indefinidamente?) seus próprios vestígios.

\section{REFERÊNCIAS}

CHARTIER, Roger. Práticas de leitura. Tradução de Cristiane Nascimento. São Paulo: Estação Liberdade, 2011.

ECO, Umberto. Lector in fabula. São Paulo: Perspectiva, 1988.

. Obra aberta: forma e indeterminação nas poéticas contemporâneas. Tradução de Giovanni Cutolo. 8. ed. São Paulo: Perspectiva, 1991.

FLEXOR, C. Appbook Raízes: bibliogênese e devir livro. 2012. 179 f. Dissertação (Mestrado) Faculdade de Artes Visuais, Universidade Federal de Goiás, Goiânia, 2012. 
FLEXOR, C. Da ontologia livresca à experiência da leitura em contexto digital: entre a consonância e o conflito. 216 f. Tese (Doutorado) - Faculdade de Artes Visuais, Universidade Federal de Goiás, Goiânia, 2018.

LÉVY, Pierre. Cibercultura. São Paulo: Ed. 34, 1999.

MANOVICH, Lev. The language of the new media. Massachusetts: MIT Press, 2002.

PLAZA, Julio. Arte e interatividade: autor-obra-recepção. Mai 2000. Disponível em: <http://www.plural.com.br/jplaza/texto01.m[18nov2003]>. Acesso em: abr. 2018.

SANTAELLA, Lúcia. Comunicação ubíqua: repercussões na cultura e na educação. São Paulo: Paulus, 2013.

Doutora em Arte e Cultura Visual pela Universidade Federal de Goiás (UFG), professora da Faculdade de Comunicação da Universidade de Brasília (UNB) e colaboradora do Programa de PósGraduação em Comunicação da Universidade Federal de Sergipe (UFS).

\section{@ $\odot \odot$}

Esta obra está licenciada com uma Licença

Creative Commons Atribuição-NãoComercial-CompartilhaIgual 4.0 Internacional 